\title{
Os desafios da governança em rede no âmbito do Circuito Liberdade
}

\author{
Vinícius Henrique Campos Senra \\ Secretaria de Estado de Cultura de Minas Gerais \\ Kamila Pagel Oliveira \\ Fundação João Pinheiro (FJP)
}

Inaugurado em 2010, o Circuito Liberdade é um projeto cultural composto por um conjunto amplo e diversificado de espaços culturais. Localizado na Praça da Liberdade, em Belo Horizonte, o Circuito Liberdade é formado por uma complexa rede de atores, públicos e privados, sendo um de seus principais desafios o gerenciamento desse conjunto de espaços, em uma perspectiva de governança em rede, de modo a conferir um caráter integrado ao projeto. Este artigo tem o objetivo de analisar as ações, estratégias e instrumentos de governança em rede adotados pelo Circuito, a partir da realização de pesquisa documental, observação participante e aplicação de questionário aos gestores dos espaços em funcionamento. Conclui-se que a gestão do Circuito já realiza ações para a articulação entre os seus espaços, mas que ainda se faz necessária a adoção de outras estratégias de governança em rede, tais como: a melhoria da comunicação interna, a disseminação do projeto para além do nível estratégico do Circuito e a maior participação da sociedade civil, ou a consolidação das existentes para garantir a unidade do Circuito, pois prevalecem ações particulares e isoladas dos espaços culturais.

Palavras-Chave: gestão pública, governança em rede, Circuito Liberdade

[Artigo recebido em 30 de novembro de 2017. Aprovado em 29 de novembro de 2018.] 
Inaugurado en 2010, el Circuito Liberdade se compone de una amplia y diversa gama de equipamientos culturales. Situado en la Plaza de la Libertad, en Belo Horizonte, el Circuito Libertade es formado por una compleja red de actores, públicos y privados, siendo uno de sus principales desafíos la gestión de ese conjunto de espacios, en una perspectiva de la gobernanza de red, dando un carácter integrado del proyecto. Por lo tanto, el trabajo tuvo como objetivo analizar las acciones, estrategias e instrumentos de gobernanza de red adoptadas por el circuito, realizando: investigación documental, cuestionario a los administradores de equipos ya instalados y la observación participante. Se concluyó que el Circuito ha celebrado las medidas de gestión para la articulación entre sus espacios, pero aún es necesario adoptar otras estrategias de gobernanza en red, tales como: la mejora de la comunicación interna, la diseminación del proyecto más allá del nivel estratégico del Circuito y la mayor participación de la sociedad civil, o la consolidación de las existentes con el fin de garantizar la unidad del Circuito, ya que prevalece acciones privadas y aisladas de los equipos.

Palabras clave: gestion publica, gobernanza de red, Circuito Liberdade

Opened in 2010, the Circuito Liberdade is a cultural project composed of a wide and diverse range of cultural centers. Located in Praça da Liberdade, in Belo Horizonte, the Circuito Liberdade is formed by a complex network of public and private actors, and one of its main challenges is the management of this set of spaces, in a perspective of network governance, in order to give an integrated character to the project. This article aims to analyze the network governance actions, strategies and instruments adopted by Circuito, as from a documental analysis, a participant observation and the application of a questionnaire to the headmanagers of the cultural spaces already openned. It is concluded that Circuito already carries out management actions for the articulation between its spaces, but it's necessary to adopt others network governance strategies, such as improving internal communication, disseminating of the project beyond the strategic level of the Circuit, and increasing participation of civil society, or to consolidate the existing ones in order to ensure the unit of the project, because private and isolated actions of cultural spaces still prevail.

Keywords: public management, governance network, Circuito Liberdade 


\section{Introdução}

As relações interorganizacionais na esfera pública se configuraram, tradicionalmente, por relações verticais entre os níveis de governo. Nas últimas décadas, porém, um conjunto de mudanças gerou novas demandas para a gestão governamental, que não podiam mais ser respondidas apenas pelo paradigma vigente de comando e controle sobre estruturas formais (RHODES, 1996; O'TOOLE, 2010; RADIN, 2010).

Os governos passaram a buscar parcerias com empresas privadas ou organizações sem fins lucrativos para enfrentar a maior complexidade das demandas e dos programas públicos, de modo que essas novas interações fossem capazes de suprir as lacunas em sua capacidade gestora interna (O'TOoLE, 2010). O foco da gestão desviou-se, assim, para as relações horizontais e transversais, desenvolvendo-se redes interorganizacionais formadas por atores governamentais e não governamentais. Como resultado dessas mudanças, os governos se tornaram mais flexíveis, mas passaram a se encontrar no topo de relações público-privadas complexas, cujas dimensões são pouco claras, e sobre cujo sistema eles têm pouco controle real, exigindo-se, pois, estratégias específicas de gestão (RHODES, 1996).

Desse modo, surge uma nova abordagem de governança, aqui denominada "Governança em Rede", baseada em acordos fundamentados na interdependência mútua de recursos e no compartilhamento de poder sem centro de autoridade, na colaboração, negociação e ilimitado fluxo de informações entre diferentes atores organizacionais (VIGODA, 2002; BINGHAM et al., 2005; RADIN, 2010; SMITH, 2010).

Entende-se a rede como um grupo de três ou mais organizações legalmente autônomas que trabalham juntas para alcançar não apenas seus próprios objetivos, mas também um objetivo coletivo, visando à obtenção de resultados que normalmente não poderiam ser alcançados por participantes individuais, agindo de forma independente. A atuação em rede envolve a interação social, conectividade, colaboração, ação coletiva, confiança e cooperação de seus membros, além de mecanismos de gestão e governança (PRovan et al., 2007; PROVAN; KENIS, 2007).

Em Minas Gerais, a "Governança em Rede" foi prevista no Terceiro Ciclo da Reforma Administrativa (2011-2014), denominada Choque de Gestão, a partir de um arranjo institucional denominado Estado em Rede, no qual o governo atuaria em parceria com outras esferas da sociedade, incluindo organizações não governamentais e a sociedade civil (MINAS GERAIS, 2012). Nesse contexto, destacavase o Projeto Estratégico Circuito Cultural Praça da Liberdade, que representa um conjunto de espaços culturais, com acervos permanentes e/ou temporários de 
visitação gratuita e uma programação dinâmica, localizados em uma área de valor simbólico, histórico e arquitetônico de Belo Horizonte: a Praça da Liberdade.

O Circuito foi inaugurado em 2010 pela Secretaria de Estado de Cultura de Minas Gerais (SEC), a partir da reforma dos edifícios do entorno da Praça da Liberdade, que abrigavam as secretarias de estado desde a inauguração da capital mineira, e da adaptação desses em espaços culturais de livre acesso do público. O projeto pressupôs desde sua origem a parceria do governo estadual com a iniciativa privada, na medida em que alguns imóveis foram cedidos a empresas financiadoras para implantação e manutenção dos respectivos espaços culturais.

A partir de junho de 2012, o Circuito passou a ser cogerido por uma Organização da Sociedade Civil de Interesse Público (Oscip), o Instituto Cultural Sérgio Magnani (ICSM), por meio de um Termo de Parceria celebrado com o Estado de Minas Gerais, representado pela SEC.

Em 21 de março de 2015, o Governo do Estado de Minas Gerais, por intermédio da SEC, rescindiu o Termo de Parceria com o ICSM na gestão compartilhada do Circuito instituindo o Instituto Estadual do Patrimônio Histórico e Artístico de Minas Gerais (lepha-MG), fundação sem fins lucrativos vinculada à SEC, como entidade gestora do projeto, que passou a se chamar Circuito Liberdade ${ }^{1}$.

Essa complexa rede de atores e relacionamentos impõe um desafio para a gestão pública mineira, uma vez que o conjunto de espaços culturais é bastante heterogêneo, desde a forma de gestão de cada espaço - público e privado - até os próprios serviços culturais oferecidos por cada um. Não desconsiderando a importância das particularidades de cada espaço, uma abordagem de governança em rede se torna necessária frente a esse desafio de gestão, no sentido de alcançar maior integração dos espaços que compõem o Circuito.

Considerando tal contexto, a pergunta de pesquisa que norteia este trabalho é: em que medida o Circuito Liberdade realiza o gerenciamento de seus espaços culturais, a partir de uma perspectiva de governança em rede?

Constitui-se objetivo deste artigo analisar as ações, estratégias e instrumentos adotados pelo Circuito Liberdade para realizar a articulação do conjunto de espaços culturais heterogêneos que o compõem, bem como eventuais obstáculos e dificuldades para se alcançar uma adequada governança em rede.

Cabe destacar que o presente artigo é baseado em pesquisa realizada no segundo semestre de 2013, representando, pois, o cenário desse período em questão.

${ }^{1}$ Decreto $n^{\circ} 46.923$, de 29 de dezembro de 2015 
De acordo com Provan e Kenis (2007), estudar como as redes funcionam é importante para compreender os resultados por elas produzidos. Ainda de acordo com Provan et al. (2007), embora haja vasta literatura sobre essa temática, o estudo empírico sobre redes interorganizacionais ainda é raro. Nesse sentido, buscouse com este estudo trazer contribuições para a prática de implementação dessa política pública - Circuito Liberdade - na medida em que se explicitam seus desafios e paradoxos, permitindo uma reflexão sobre a possibilidade de aprimoramento no alcance de seus resultados.

Além disso, busca-se uma contribuição teórica, a partir da análise de um caso concreto, dando subsídio para compreender de forma mais aprofundada e reflexiva como ocorre a implementação de políticas públicas em contexto interorganizacional. Tais contribuições - teórica e prática - podem auxiliar, pois, a implementação de outras políticas públicas adotadas em uma perspectiva de governança em rede.

\section{Compreendendo o conceito de governança em rede}

Há algumas décadas, o aumento da complexidade do quadro urbano e social fez com que a máquina pública recebesse uma demanda cada vez mais densa e diversificada por parte da população para mudança nos serviços públicos oferecidos. A alteração na percepção dos cidadãos e dos próprios governos quanto ao seu papel nas sociedades democráticas, e críticas à estrutura burocrática hierárquica tradicional, com poderes concentrados no topo das organizações, contribuíram para o desenvolvimento de um movimento com foco no desempenho e nos resultados da administração pública. A reforma administrativa que derivou desse movimento ficou conhecida como New Public Management (NPM) (RADIN, 2010; O'Toole, 2010).

Desenvolveu-se no setor público, assim, um conjunto de mudanças administrativas que alteraram significativamente a governança e a própria gestão pública. As mudanças apoiadas pelo movimento global de reforma na administração pública apresentaram novas demandas para a gestão intergovernamental, que não podiam mais ser respondidas apenas pelo paradigma tradicional de comando e controle sobre estruturas formais, cedendo espaço para programas públicos que envolvessem uma grande variedade de atores, tanto governamentais quanto não governamentais (RHODES, 1996).

Alguns autores, todavia, apontam diversos limites da NPM, afirmando que esta reforça a separação entre política e administração, possui foco intraorganizacional e não considera a dimensão sociopolítica da gestão, além de se configurar como pouco democrática (Brugué, 2004; PAUla, 2005; CARneiro; MenicucCI, 2011). 
De acordo com Denhardt e Denhardt (2000), a Nova Gestão Pública não contempla a resolução de questões fundamentais presentes na velha gestão pública, caracterizada como burocrática e hierárquica. Para o autor, questões como neutralidade da política, estrutura organizacional centralizada, decisões tomadas de cima para baixo, sistemas fechados que limitam a participação dos interessados e a centralidade do poder governamental nas relações sociais persistem nas administrações públicas contemporâneas, não obstante as ações implementadas na busca de uma nova gestão pública.

Assim, autores defendem que a melhoria da gestão pública passa por buscar um reformismo mais aberto, pautado na democratização do Estado e na implementação efetiva de mecanismos de accountability e participação social (RHODES, 1996; Denhardt; Denhardt, 2000; PAula, 2005; Carneiro; MenicucCl, 2011).

A solução dessas limitações vai ao encontro de diversos estudos contemporâneos que tratam do conceito de governança. O termo "governança", tradicionalmente usado como sinônimo de governo, passou por um redirecionamento em sua utilização (STOKER, 1998). A partir dos sentidos da palavra "governo", como atividade ou processo de governar, condição de normas ordenadas e forma, método ou sistema pelo qual uma determinada sociedade é governada, se estabelece o conceito de "governança" como uma mudança no sentido do governo, referindo-se a um novo processo de governar, ou uma condição alterada da regra ordenada, ou o novo método pelo qual a sociedade é governada (RHODES, 1996, p. 652-653).

A governança pública passa a indicar uma nova prática para o exercício da administração pública, na qual é dado maior enfoque à atuação via redes de organizações ou atores sociais, sendo estes, mais autônomos, independentes e regulados, havendo a definição de objetivos conjuntos e de guias de ação (STREIT; KLERING, 2005 apud SLOMSKI et al., 2008). Os atos do governo passam a ser realizados em conjunto com grupos e organizações privadas e sem fins lucrativos, com vistas a buscar soluções para os problemas que as comunidades enfrentam (RHODES, 1996; DENHARDT; DENHARDT, 2000).

Nesse novo contexto, o papel do governo é transformado, pois possui a função de controlar a configuração da agenda, trazendo os jogadores adequados para a mesa por meio de coalizões com agências públicas, organizações privadas e sem fins lucrativos, além da função de facilitação, negociação e intermediação para alcançar as soluções dos problemas públicos. O governo torna-se simplesmente outro jogador, mesmo que um jogador de extrema importância no processo de direcionamento e mudança das políticas públicas e, indiretamente, da sociedade (DENHARDT; DENHARDT, 2000). 
A nova abordagem da governança envolve o conceito de redes autoorganizadas, que complementariam mercado e hierarquia como estruturas de governo para alocar recursos e exercer controle e coordenação. As redes seriam formadas a partir de um conjunto complexo de organizações autogerenciado e autônomo, com alto grau de liberdade, mas também de autorresponsabilidade, deslocando-se o foco da gestão pública para o gerenciamento das relações interorganizacionais e a negociação de interesses e objetivos comuns. Para efeito do que se propõe neste artigo, essa nova abordagem da governança será denominada "Governança em Rede" (RHODES, 1996).

De acordo com Provan e Kenis (2007), as vantagens da governança em rede tanto no setor público quanto no privado são consideráveis, e incluem a utilização mais eficiente de recursos, maior capacidade de planejar e abordar problemas complexos, maior competitividade e melhores serviços para o público-alvo.

Como redes autoorganizadas, a governança em rede seria delineada pelos seguintes aspectos: interdependência entre organizações (do setor público, privado ou voluntárias); interações contínuas e influência mútua entre os membros; interações do tipo jogos, baseadas na confiança e regulamentadas por regras acordadas pelos participantes da rede; e grau significativo de autonomia em relação ao Estado; complexidade da tomada de decisões por envolver múltiplos atores; indefinição de limites e responsabilidades; dependência de poder, sendo necessária a troca de recursos e a negociação de objetivos comuns (RHODES, 1996; StOKER, 1998; PROVAN; KENIS, 2007; Provan et al., 2007).

A governança em rede envolveria, portanto, a utilização de determinadas estratégias e instrumentos que alcancem a cooperação e o compartilhamento de interesses entre as diversas instituições envolvidas (RHODES, 1996). Observa-se uma ênfase em certas habilidades, como negociação e persuasão, colaboração e capacitação, além de mediação, gestão de conflitos, escuta ativa, facilitação, construção do consenso e execução de políticas de colaboração (VIGODA, 2002; BINGHAM et al., 2005; KLIJN, 2007).

De acordo com Provan e Kenis (2007), é possível identificar três tipos de governança em rede, sendo eles: governança compartilhada, organização líder e organização administrativa de redes (Network Administrative Organization - NAO).

A governança compartilhada e a organização líder são formas de governança interna, ou seja, realizada pelos próprios membros da rede. Na compartilhada, no entanto, a rede é governada coletivamente pelos próprios membros, havendo uma distribuição igualitária e descentralização de autoridade e poder (PROVAN; KENIS, 2007). 
No tipo organização líder, por sua vez, um único participante da rede assume o papel de liderança e coordenação, sendo a gestão altamente centralizada e com assimetria de poder. O papel da organização líder emerge dos membros da rede, sendo que um deles assume a liderança por ter legitimidade ou recursos diferenciados dos demais (PROVAN;KENIS, 2007).

Por fim, o tipo organização administrativa de redes (Network Administrative Organization-NAO) configura-se como uma entidade administrativa criada especificamente para governar a rede e suas atividades. Apesar de os membros da rede interagirem uns com os outros, como acontece com a organização líder, o modelo NAO é centralizado. O gerenciador possui um papel fundamental na coordenação e manutenção da rede e ao contrário do modelo de Organização líder, o NAO não é uma organização membro que presta seus próprios serviços, mas é uma entidade externa. O NAO pode ser uma entidade governamental, ou uma organização sem fins lucrativos, mesmo quando a rede é formada por empresas com fins lucrativos. O NAO administrado pelo governo geralmente é utilizado quando a rede é formada pela primeira vez para estimular o seu crescimento, para obtenção de financiamento e para auxílio no alcance das metas da rede (PROVAN; KENIS, 2007).

De acordo com Provan e Kenis (2007), a escolha do tipo de governança a ser utilizado depende de quatro fatores: confiança, número de participantes, nível de consenso dos objetivos da rede, e a natureza da tarefa, o que irá identificar a necessidade de competências de gestão em rede. A Figura 1 representa a relação entre essas variáveis e o tipo de governança mais adequado:

Figura 1 - Fatores chave de efetividade dos tipos de governança em rede

\begin{tabular}{lllll}
\hline $\begin{array}{l}\text { Governance } \\
\text { Forms }\end{array}$ & Trust & $\begin{array}{l}\text { Number of } \\
\text { participantes }\end{array}$ & $\begin{array}{l}\text { Goal } \\
\text { consensus }\end{array}$ & $\begin{array}{l}\text { Need for } \\
\text { network-level } \\
\text { competencies }\end{array}$ \\
\hline $\begin{array}{l}\text { Shared } \\
\text { governance } \\
\text { lead } \\
\text { organization }\end{array}$ & $\begin{array}{l}\text { High density, } \\
\text { Low density, } \\
\text { highly } \\
\text { centralized }\end{array}$ & $\begin{array}{l}\text { Few moderate } \\
\text { number }\end{array}$ & $\begin{array}{l}\text { High } \\
\text { moderately } \\
\text { low }\end{array}$ & Low moderate \\
\hline $\begin{array}{l}\text { Network } \\
\text { administrative } \\
\text { organization }\end{array}$ & $\begin{array}{l}\text { Moderate } \\
\text { density, NAO } \\
\text { monitored by } \\
\text { members }\end{array}$ & $\begin{array}{l}\text { Moderate to } \\
\text { many }\end{array}$ & $\begin{array}{l}\text { Moderately } \\
\text { high }\end{array}$ & High \\
\hline
\end{tabular}

Fonte: Provan e Kenis (2007, p. 237) 
Da Figura 1 depreende-se que, quanto maior a confiança entre os membros e o consenso quanto aos objetivos da rede, mais adequado é o modelo de governança compartilhada, permitindo que a autoridade e o poder de decisão sejam igualmente distribuídos. Níveis moderados de confiança e de consenso quanto aos objetivos tornam mais adequado o modelo NAO, pois exige a participação de um membro externo para garantir tais fatores. A organização líder é adequada quando o nível de confiança é baixo e o consenso é de baixo a moderado, exigindo uma centralização maior de autoridade e poder de decisão. Quanto ao número de participantes, quanto maior o número de membros, mais adequado tende a ser o modelo NAO. Números menores de membros provavelmente indicam menor diversidade e conflitos e maior diálogo, o que possibilita uma governança compartilhada. Quanto à necessidade de competência de rede, a governança compartilhada será menos provável de ser uma forma eficaz de governança quando os requisitos de tarefas interdependentes são altos. Por outro lado, a interdependência das atividades favorece a organização líder ou o modelo NAO, que são mais capazes de desenvolver competências relacionadas com as necessidades coletivas, ou seja, ao nível da rede (PROVAN; KenIS, 2007).

Diante disso, um dos desafios para o alcance da eficácia da governança em rede consiste justamente na identificação do tipo mais adequado, conforme as características de cada contexto (PROVAN; KENIS, 2007).

O paradoxo da atual perspectiva de governança em rede é que, mesmo onde o governo desenvolve um código operacional adequado, a governança pode ser insuficiente e o fracasso pode ainda ocorrer. Tensões e dificuldades com as instituições envolvidas, inadequações nas organizações que preenchem as lacunas entre o setor público, privado e voluntário, falhas de liderança, diferenças na escala de tempo e horizontes entre os parceiros-chave, e a profundidade dos conflitos sociais podem fornecer as sementes para o fracasso da governança. Assim, a governança convive com a incerteza, projetando e reconhecendo tanto o potencial, quanto as limitações das instituições (STOKER, 1998).

E é nesse contexto de uma perspectiva de governança em rede que se destaca a gestão do Circuito Liberdade, projeto cultural do Governo de Minas Gerais, cujo modelo é baseado em parcerias com a iniciativa privada e com organizações não governamentais sem fins lucrativos, e que por esse motivo impõe vários desafios à gestão pública mineira. 


\section{Procedimentos metodológicos}

O presente artigo caracteriza-se por um estudo de caso que teve como objeto de análise o Circuito Liberdade; mais especificamente as estratégias adotadas para a articulação e o gerenciamento dos espaços culturais que o compõem, em uma perspectiva de governança em rede. Este artigo possui como unidade de análise o Circuito como um todo, visto como uma rede que demanda instrumentos de gestão e governança.

Quanto aos procedimentos técnicos utilizados, a pesquisa envolveu três métodos principais: pesquisa bibliográfica, pesquisa documental e levantamento de campo (com observação participante e aplicação de questionários).

Inicialmente, foi realizada uma revisão bibliográfica sobre governança, relações interorganizacionais, e estratégias de gestão em rede, que forneceu embasamento para a análise. A pesquisa documental, por sua vez, teve como objetivo resgatar a história do Circuito e compreender as especificidades de cada espaço cultural, o que demandou a análise de documentos como: Plano Geral do Circuito, Planejamento Estratégico do Circuito, memoriais descritivos e planos de projetos dos respectivos espaços, Regimento Interno, Termo de Parceria firmado entre a Secretaria de Estado de Cultura (SEC) e o Instituto Cultural Sérgio Magnani (ICSM), Política Cultural e Educativa do Circuito, além de informações presentes em outros documentos e apresentações institucionais. A pesquisa de campo, por sua vez, foi realizada no segundo semestre de 2013, por meio de observação participante, na condição de estagiário de administração pública, com vivência no dia-a-dia do Circuito, participação em reuniões, inclusive do Comitê Gestor, tarefas cotidianas e contato com os diversos atores envolvidos dos diferentes espaços.

Por fim, foi realizada a aplicação de um questionário, formado por quatorze questões, abertas e de múltipla escolha, com os gestores dos espaços culturais, com a finalidade de verificar qual a percepção deles em relação às estratégias de gestão do Circuito, bem como aos eventuais obstáculos e ao papel que desempenham no contexto de governança em rede. Os dados coletados foram tabulados e analisados majoritariamente de forma quantitativa, reforçados pelas respostas das questões abertas, conforme será apresentado adiante, com os resultados.

Nas questões de múltipla escolha buscou-se entender as seguintes questões: compreensão do pesquisado sobre o que significa fazer parte do Circuito Liberdade; nível de conhecimento a respeito dos demais equipamentos culturais dos gestores e das equipes; percepção sobre a comunicação interna do Circuito; percepção sobre a adoção de possíveis estratégias/ações para melhorar a integração do Circuito e fortalecer sua identidade. 
Já entre as questões abertas, ressaltam-se: os benefícios, para cada espaço cultural, de fazer parte do Circuito Liberdade; a contribuição de cada espaço para a integração dos equipamentos e o fortalecimento da identidade do Circuito; estratégias que o Circuito poderia ou deveria adotar para melhorar a integração de seus equipamentos e fortalecer sua identidade.

Além disso, foram utilizadas duas questões de classificação, na qual os gestores deveriam classificar os três itens mais significativos de uma listagem apresentada, assinalando 1 para o principal, 2 para o segundo e 3 para o terceiro mais significativo, sendo elas: Quais estratégias/ações mais contribuem para a integração do Circuito e o fortalecimento de sua identidade? e Quais fatores mais dificultam a integração do Circuito e o fortalecimento de sua identidade?.

Optou-se pela aplicação de um questionário pela dificuldade de disponibilidade dos gestores dos espaços para responder entrevistas qualitativas. O questionário foi encaminhado por e-mail para os gestores dos doze espaços em funcionamento do Circuito na época² ${ }^{2}$ não tendo sido bem-sucedido. Uma nova tentativa foi feita presencialmente durante uma reunião de Comitê Gestor, na qual foram obtidas nove respostas.

\section{Histórico do Circuito: um projeto cultural inovador}

A Praça da Liberdade é um dos polos simbólicos de Belo Horizonte, sendo uma das poucas áreas da capital que ainda guarda referências significativas de sua criação, em 1897. O seu entorno, tombado em 1977, abriga um conjunto arquitetônico e paisagístico de grande valor histórico, com edificações construídas para abrigar a sede do poder executivo mineiro da nova capital. Ao longo do século, a Praça sofreu uma sobreposição de sentidos, foi palco de movimentos cívicos e manifestações políticas, e vivenciou o avanço desordenado das feiras de artesanato, chegando à década de 1990 com um quadro visível de degradação.

Após obras de restauração em 1992, a Praça retomou o seu papel tradicional no cotidiano belo-horizontino, mas os prédios históricos continuavam tendo seus acessos limitados às funções do serviço público estadual, que com a inevitável ampliação de sua máquina, também passava a exigir um espaço maior e mais adequado às suas necessidades (PEREIRA, 1998).

A partir disso, surgiu a ideia de adaptação dos edifícios públicos do entorno da Praça da Liberdade para um novo uso, que ajudasse a preservar o seu patrimônio

\footnotetext{
${ }^{2}$ Com a entrada do BDMG Cultural em 2015, da Academia Mineira de Letras em 2016, e da reabertura do edifício Rainha da Sucata, que abriga o Centro de Informação ao Visitante e o HUB Minas Digital, o Circuito é formado hoje por 15 espaços culturais.
} 
histórico, arquitetônico, artístico e cultural. Tal proposta foi apresentada no plenário do Senado pelo ex-governador de Minas Gerais e, na ocasião, senador, Francelino Pereira, no dia 12 de dezembro de 1997. O projeto intitulado "Requalificação da Praça para o Terceiro Milênio: A criação do Espaço Cultural da Liberdade" objetivava transformar a Praça da Liberdade no endereço da cultura mineira, adaptando todos os prédios históricos do entorno em espaços culturais de livre acesso à população (PEREIRA, 1998).

No projeto apresentado, foram definidas possíveis ocupações para cada um dos prédios e ações necessárias à operacionalização. Entretanto, a ideia não foi colocada em prática imediatamente, sendo retomada apenas em 2003, quando o Projeto "Corredor Cultural da Praça da Liberdade e o Centro Cultural da Casa do Conde de Santa Marinha" foi incluído na carteira de Projetos Estruturadores do Governo (MinAS GerAIS, 2003), e com a previsão também da Cidade Administrativa de Minas Gerais, na região norte da cidade, para onde seria transferida a máquina pública.

Para viabilizar tal projeto cultural, o Decreto $\mathrm{n} N$ 43.263/2003 instituiu uma Comissão Especial de Estudos com o objetivo de planejar, coordenar e acompanhar a execução do projeto, sendo composta por representantes dos seguintes órgãos: SEC, responsável pela coordenação executiva; Secretaria de Estado de Planejamento e Gestão (Seplag); Secretaria de Estado de Governo (Segov); Secretaria de Transportes e Obras Públicas (Setop); Instituto Estadual do Patrimônio Histórico e Artístico de Minas Gerais (Iepha-MG); Prefeitura de Belo Horizonte; e Instituto de Arquitetos do Brasil (IAB); e como Presidente Honorário da Comissão, o precursor da ideia, Francelino Pereira.

Dois anos após o início dos trabalhos da Comissão, foi elaborado um Plano Geral com diretrizes básicas a serem seguidas para o funcionamento do Projeto, denominado "Circuito Cultural Praça da Liberdade". O Plano Geral estabeleceu um modelo de gestão e financiamento do Circuito, no qual cada espaço cultural seria administrado por uma entidade gestora específica (pública ou privada), responsável pela elaboração dos projetos conceituais, físicos e técnicos de suas instalações, pela execução, manutenção e financiamento das mesmas e pela programação, execução e financiamento de suas atividades específicas, com seus próprios recursos e/ou com o apoio de terceiros.

O Projeto Circuito Cultural Praça da Liberdade tem como objetivo instalar nos prédios que serão disponibilizados na Praça e suas adjacências, um conjunto amplo, variado e integrado de centros e atividades culturais, artísticas, educacionais, de lazer cultural e de turismo cultural, tais como museus, centros de memória, salas de espetáculos e exibições, áreas de 
exposições, espaços para oficinas, cursos e ateliês abertos, áreas de lazer, de permanência e de convivência, e áreas de serviços, alimentação e comercialização de produtos culturais (PLANo GERAL, 2005).

A implantação do Circuito seria realizada em 2006, mas a concepção do projeto e as estratégias de implementação foram objeto de controvérsias, e o Circuito recebeu uma série de embargos promovidos pelo Ministério Público, sob a alegação de descaracterização dos prédios históricos, ficando suspenso até o segundo semestre de 2009, quando o projeto foi aprovado e as obras de revitalização reiniciadas (FONSECA, 2009).

O Circuito foi inaugurado em 2010, com a implantação do Memorial Minas Gerais, em parceria com a Vale, no antigo prédio da Secretaria da Fazenda, do Museu das Minas e do Metal $^{3}$, em parceria com a EBX, na antiga Secretaria de Educação, e do Espaço TIM UFMG do Conhecimento) ${ }^{4}$, na antiga reitoria da Universidade Estadual de Minas Gerais (UEMG), em parceria com a TIM e a Universidade Federal de Minas Gerais (UFMG), além dos espaços públicos já existentes: Arquivo Público Mineiro, Biblioteca Pública Estadual Luiz de Bessa ${ }^{5}$ e Palácio da Liberdade.

Em 2013, quando da realização da pesquisa base para o presente artigo, o Circuito contemplava 12 espaços culturais em funcionamento, a saber: Arquivo Público Mineiro, Biblioteca Pública Estadual Luiz de Bessa, Casa Fiat de Cultura, Cefart Liberdade, Centro Cultural Banco do Brasil, Centro de Arte Popular Cemig, Espaço do Conhecimento UFMG, Horizonte Sebrae - Casa da Economia Criativa, Memorial Minas Gerais Vale, MM Gerdau - Museu das Minas e do Metal, Museu Mineiro e Palácio da Liberdade ${ }^{6}$, espaços bastante heterogêneos no que tange às suas instituições gestoras, seus objetivos e respectivas propostas de intervenção.

Frente a essa complexidade, o Circuito foi cogerido pelo Instituto Cultural Sérgio Magnani (ICSM), durante 2 anos e meio a partir de junho de 2012, por meio de um termo de parceria celebrado entre essa organização da sociedade civil de interesse público (Oscip) e o Estado de Minas Gerais, representado pela SEC.

O termo de parceria teve como objeto a gestão compartilhada do Circuito, de modo a administrar as atividades comuns a todos os espaços, fiscalizar o cumprimento das parcerias celebradas com as entidades gestoras, promover ações

\footnotetext{
${ }^{3}$ Atualmente MM Gerdau - Museu das Minas e do Metal, em parceria com a Gerdau.

${ }^{4}$ Atualmente Espaço do Conhecimento UFMG, com o término da parceria com a TIM.

${ }^{5}$ Atualmente Biblioteca Pública Estadual de Minas Gerais.

${ }^{6}$ Com a entrada do BDMG Cultural em 2015, da Academia Mineira de Letras em 2016, e da reabertura do edifício Rainha da Sucata, que abriga o Centro de Informação ao Visitante e o HUB Minas Digital, o Circuito é formado hoje por 15 espaços culturais (Vide nota 5).
} 
de comunicação, promoção de eventos, captação e geração de recursos. A equipe do estado e do ICSM constituíam o denominado Núcleo Articulador, sendo a primeira responsável pelos investimentos ao projeto e a segunda pelas ações rotineiras de comunicação, programação cultural e educativa do Circuito.

Utilizando-se da definição de Provan e Kenis (2007), pode-se dizer que o Circuito possui uma forma de governança do tipo NAO, a partir da qual o Estado de Minas Gerais, por meio da Secretaria de Cultura, possui, nesse projeto, autoridade para coordenar e gerenciar as ações dos membros da rede. A SEC configura-se como um importante ator, no entanto, não pode ser considerada como os demais espaços culturais pois sua atuação é exclusivamente de coordenação e não de oferta direta de um serviço. Além disso, seu papel de autoridade e legitimidade não se origina de uma escolha dos demais membros, mas sim do fato de ser um representante direto do Estado de Minas Gerais.

Essa parceria com a iniciativa privada e com o terceiro setor foi prevista seguindo a tendência mundial advinda da Nova Gestão Pública que, posteriormente, avança para uma governança em rede, conforme exposto, na qual os governos buscam parcerias com empresas privadas ou organizações sem fins lucrativos, para enfrentar a maior complexidade das demandas e para suprir a sua baixa capacidade gestora interna (RHodes, 1996; DenhaRdT; DenhardT, 2000; O’Toole, 2010). Enquanto as empresas mantenedoras assumem um importante papel de financiamento da política pública, o Estado continua sendo essencial para dar legitimidade, respaldo político e técnico ao projeto, e a presença da OSCIP é fundamental para tornar mais ágil e flexível a execução dos recursos públicos (ALVES, 2009).

O Estado apresenta uma preponderância sobre a estrutura analítica do projeto Circuito, na medida em que os parceiros podem ser substituídos se suas atribuições não forem cumpridas de forma efetiva, e a rede pode ser desfeita se o Estado não cumprir com suas obrigações. Entretanto, com a consolidação do projeto, a tendência é que o papel preponderante do Estado diminua, visto que o projeto passa a adquirir uma experiência e reconhecimento que possibilita sua existência de forma mais autônoma (ALVES, 2009). Nesse caso, conforme afirmam Provan e Kenis (2007), à medida que se ganha maior confiança e consenso das metas da rede há uma tendência de caminhar em direção ao tipo de governança compartilhada, em que há uma distribuição equilibrada e equitativa de recursos e poder.

Não obstante, o modelo de gestão do Circuito acabou por se tornar bastante complexo, sendo resultado da ação de diversos atores. Além disso, por meio da análise dos diferentes instrumentos jurídicos assinados entre o governo e as instituições mantenedoras dos espaços culturais, observa-se que inicialmente havia poucas prerrogativas no sentido de uma gestão em conjunto, se concentrando nas 
ações específicas de cada espaço. Apenas anos mais tarde, a preocupação inicial com a negociação e a celebração dos convênios e com a restauração e a reforma dos edifícios cedeu espaço para desafios relacionados à gestão e governança do Projeto como um todo; desafios de alinhamento e articulação de todos os envolvidos, de modo a mobilizá-los para manter a unidade proposta pelo projeto.

Tornou-se coerente, dessa forma, a adoção, pelo Núcleo Articulador do Circuito, de ações e estratégias de gestão, seguindo uma perspectiva de Governança em Rede, que serão analisadas a seguir. Tal perspectiva é pertinente para consolidar o caráter integrado pretendido ao projeto perante os interessados e a população, e não apenas implementar e gerenciar de forma isolada cada um dos espaços.

\section{Análise dos instrumentos, ações e estratégias do Circuito Liberdade em uma perspectiva de governança em rede}

A partir da análise documental, da observação participante e da pesquisa de campo realizadas no Circuito Liberdade, foram identificados instrumentos, ações e estratégias de articulação entre seus espaços culturais e que poderiam ser avaliados sob uma perspectiva de governança em rede. Para esta análise, foi utilizada como base o questionário aplicado aos gestores dos espaços em funcionamento, que permitiu verificar qual é a percepção geral desses em relação à governança em rede do Circuito e qual o papel que cada um desempenha nesse contexto.

Cabe destacar a complexidade do conceito de "Governança em Rede" para ser brevemente transmitida aos gestores, de modo que foi utilizado o termo "integração" para se fazer entender, uma vez que já era uma palavra bastante empregada no dia-a-dia, diálogo entre gestores e reuniões do Circuito.

Como pode ser visto pelo Gráfico 1, quando questionados a respeito das estratégias de Governança em Rede, os gestores informaram que os principais instrumentos que contribuíram para a integração do Circuito foram a elaboração do Planejamento Estratégico, o estabelecimento do Comitê Gestor, as ações de marketing e comunicação do Circuito, bem como a elaboração do Regimento Interno e a sinalização externa unificada dos espaços do Circuito. 
Gráfico 1: Quais instrumentos/estratégias mais contribuem para a integração do Circuito e o fortalecimento de sua identidade?
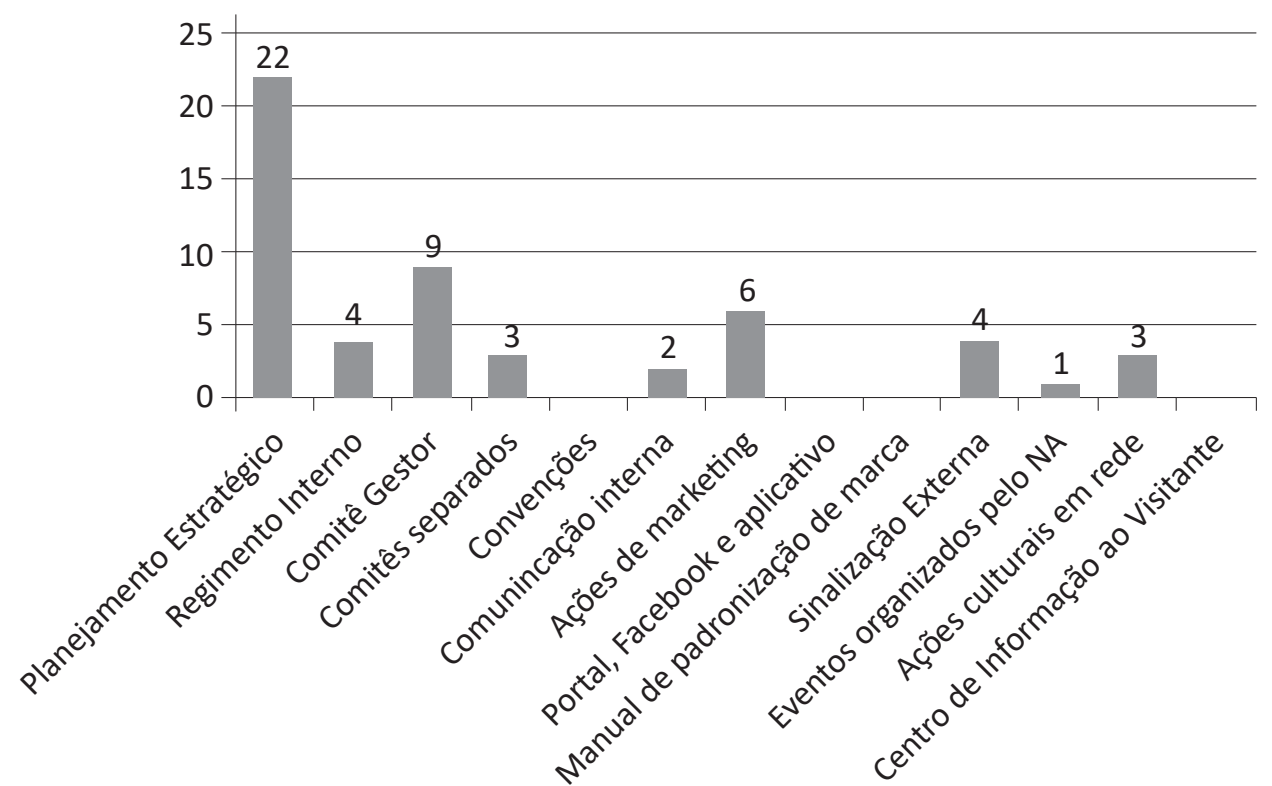

Fonte: elaboração própria

Na percepção dos respondentes, o Planejamento Estratégico foi considerado como o instrumento que mais contribuiu para a integração do Circuito. Considerando que os gestores deveriam fazer uma classificação de 3 itens, conforme explicado na metodologia, colocando 3 pontos para o item mais importante, 2 pontos para o segundo item mais importante e 1 para o terceiro, tem-se que o planejamento estratégico obteve um total de 22 pontos.

O Planejamento Estratégico do Circuito foi elaborado ao final do ano de 2011 e início de 2012, quando, pode-se dizer, foi dado o primeiro passo para a Governança em Rede, uma vez que ocorreu, pela primeira vez, uma reunião de todos os atores diretamente envolvidos no Projeto, para se pensar em estratégias de governança e tomar decisões coletivas. Fizeram parte dos seminários de planejamento estratégico membros da equipe do Estado responsável pela gestão do Circuito (nessa época, o projeto ainda não era co-gerido pelo ICSM), bem como os gestores e assessores de cada equipamento cultural já implantado ou ainda a implantar. Também participaram dos seminários, representantes da SEC, do lepha, da Companhia Mineira de Promoções (Prominas) e da Secretaria de Estado Extraordinária da Copa do Mundo (Secopa) (Planejamento, 2012).

Os trabalhos para elaboração do Planejamento Estratégico foram coordenados e desenvolvidos por uma consultoria externa contratada e visavam propor subsídios 
conceituais e técnicos, de natureza museológica, que permitissem às instituições participantes redefinirem juntas a proposição do Circuito, as potencialidades do trabalho em rede, as sinergias do Projeto, bem como requalificar as ações em grupo, visando às possibilidades de parceria e colaboração.

Foram realizados quatro encontros divididos em: apresentação teórica, estudos de caso, orientações para a redação conjunta e colaborativa das estratégias do Circuito, e fundamentos da atuação do Circuito. As avaliações realizadas ao final de cada módulo do seminário evidenciavam a relevância dos conteúdos discutidos, o envolvimento e a integração que se estabeleceu entre os participantes (Planejamento, 2012).

Os seminários de planejamento estratégico foram a primeira vez em que todos os atores e instituições diretamente envolvidas na implantação e manutenção do Circuito foram colocados juntos, para se pensar estratégias e tomar decisões coletivas, sendo também o momento de elaboração do Regimento Interno. Apesar da importância da iniciativa, cabe destacar que o encontro de todos os gestores dos espaços, bem como dos órgãos públicos diretamente envolvidos no Circuito, ocorreu apenas seis anos após a definição do modelo de gestão no Plano Geral.

Foi apenas nesse momento em que foram definidas a visão e a missão institucionais, bem como os seguintes objetivos estratégicos do Circuito:

- Atuar em rede, de forma integrada e colaborativa.

- Valorizar a diversidade das instituições, dos acervos e de suas ações.

- Desenvolver ações que promovam junto à população o acesso e o pertencimento ao Circuito.

- Favorecer a inclusão e a acessibilidade aos espaços e aos conteúdos do Circuito.

- Promover a difusão cultural e formação de público, por meio de programas científicos, culturais e educacionais de excelência.

- Estabelecer relações permanentes com a produção artístico-cultural local.

- Dialogar com os órgãos públicos municipais, estaduais e federais, visando à melhoria e à manutenção permanente do entorno - preservação patrimonial, segurança, acessibilidade e mobilidade urbana (PLANEJAMENTO, 2012).

Para chegar a essas definições, foram pensados primeiramente como era a realidade, quais eram os desejos e as possíveis sinergias do Circuito, em um cenário local, regional, nacional e internacional. Em todos os casos, se pensou em várias possibilidades de parceria e colaboração. Em um contexto local, por exemplo, foram destacados: o intercâmbio com instituições públicas e privadas; parcerias e maior integração com escolas, universidades e equipamentos culturais do entorno; 
no cenário regional, foram propostas parcerias e atuações com organizações municipais e regionais, com outros circuitos culturais e artísticos e com o turismo interestadual para Minas Gerais; para o cenário nacional, pensou-se na atuação em redes sociais e internet, em parcerias com espaços culturais de outros Estados; e no cenário internacional, poderiam ser realizados intercâmbios/convênios técnicos com outros países, nos quais o Circuito atuaria como agenciador/intermediador; o estreitamento de relações com instituições culturais internacionais; parcerias com museus, arquivos, bibliotecas e outros órgãos internacionais; a abertura de canais de intercâmbio junto aos órgãos para troca de experiências com especialistas internacionais (Planejamento, 2012).

Percebe-se que grande parte dos objetivos definidos no planejamento estratégico enfatiza a busca pela colaboração dos envolvidos, pela integração das ações, pela atuação em rede, e pelo contato com outros atores públicos e privados, todas essas características presentes no conceito de governança em rede (RHODES, 1996; VIGODA, 2002; BINGHAM, 2005; KLIJN, 2007). Não foi à toa, portanto, que o planejamento estratégico foi apontado pelos representantes dos espaços culturais como o instrumento que mais contribuiu para a governança do Circuito. Apenas um dos nove respondentes não o colocou como uma das três estratégias que mais contribuíram para a integração das ações do Circuito.

Para além da definição do perfil institucional do Circuito-visão, missão e objetivos - um dos principais resultados dos seminários para o planejamento estratégico foi a criação do Comitê Gestor, grupo representativo composto pelos gestores ou representantes dos espaços culturais e pelo gerente e outros representantes do Núcleo Articulador. As funções do Comitê Gestor são: ser o guardião da visão e da missão do Circuito; propor estratégias; acompanhar e validar os outros comitês; funcionar como um núcleo de resolução de questões extraordinárias, impasses e conflitos dos demais comitês e das instituições.

O Comitê Gestor atua como instância deliberativa nas questões de interesse comum do Circuito e tem a finalidade de discutir questões que afetam a coletividade, democratizar as discussões e concretizar a cooperação entre os seus integrantes. Nas reuniões do Comitê Gestor são discutidas questões tanto de natureza institucional, como a consolidação do Regimento Interno do Circuito, quanto de cunho prático, como a participação em grandes eventos de Belo Horizonte. Algumas vezes, entidades e/ou profissionais também são convidados às reuniões, para expor e tratar de assuntos de interesse comum, como, por exemplo, sobre possíveis abordagens sociais com os moradores em situação de rua do entorno do Circuito e sobre a possibilidade de parcerias com agências de turismo para a formação de serviços receptivos. 
O Comitê Gestor foi o segundo instrumento de gestão em rede mais assinalado pelos respondentes da pesquisa no que tange à contribuição para a integração do projeto. Como as reuniões do Comitê ocorrem com uma frequência constante, este pode ser considerado o momento oportuno e um instrumento fundamental para uma gestão em rede efetiva do Circuito, democratizando as discussões e concretizando a cooperação entre os seus integrantes, bem como a mediação de conflitos conforme prevê a literatura de Governança em Rede (RADIN, 2010). A utilização de uma espécie de comissão (como é o caso do Comitê Gestor) já havia sido apontada por Radin (2010) como um importante instrumento estrutural de integração horizontal para relações interorganizacionais.

Ainda com base no Planejamento Estratégico, foi elaborada a Política de Ocupação Cultural e Educativa do Circuito, com o objetivo de promover ações transversais, experiência de Circuito para o público a partir da articulação entre acervos e eventos compartilhados, e canais de colaboração com o setor cultural. A política visava possibilitar que os espaços, embora possuíssem equipes próprias de ação educativa e propostas culturais distintas, realizassem uma abordagem integrativa, dialogando com os demais serviços educativos, consolidando a identidade do Circuito e respeitando, portanto, o caráter de rede, característico do projeto. Propunha-se tratar da colaboração e participação realmente ativa e direta dos atores envolvidos no Circuito para a definição de estratégias em um projeto único, que gerassem experiências genuínas de um circuito integrado. Tendo em vista que até a realização da pesquisa poucas ações haviam sido realizadas com base nessa Política de Ocupação ${ }^{7}$, as "ações culturais em rede" não receberam uma votação tão expressiva pelos gestores, com relação aos instrumentos/estratégias que contribuíam para a integração do Circuito.

As ações de comunicação e marketing, indicadas como a terceira estratégia que mais contribuiu para a integração do Circuito, também podem ser vistas como estratégias para garantir a Governança em Rede, já que auxiliam na apresentação ao público do Circuito como um todo, transmitindo um caráter integrado e permitindo a consolidação do projeto. Entre outras ações, destacam-se: o portal eletrônico, principal fonte de divulgação de informações do Circuito; o aplicativo mobile para celular ou smartphone como uma extensão do portal eletrônico; demais redes sociais do Circuito, como a página do Facebook, o Instagram e o Twitter; e o toten informativo presente em todos os espaços. Podemos destacar ainda o Centro de

\footnotetext{
${ }^{7}$ A Política de Ocupação Cultural e Educativa do Circuito, no entanto, balizou todas as ações de educação e programação do Circuito no ano que se seguiu (2014), enquanto o projeto ainda era cogerido pelo ICSM, tendo produzido um grande evento em rede entre todos os espaços do Circuito. Tratou-se do Circuito Literário, realizado em novembro de 2014, Este formou uma equipe educativa gerida pelo Núcleo Articulador que realizava atividades mediadas na própria Praça da Liberdade e dialogava com as equipes educativas de todos os espaços.
} 
Informação ao Visitante, que visa atender aos visitantes de todo o Circuito.

A comunicação é classificada por Radin (2010) como uma importante ferramenta comportamental de gestão das relações interorganizacionais. Seguindo essa diretriz, foi desenvolvido o Plano de Comunicação do Circuito, com o objetivo de garantir uma comunicação aplicável a todos os espaços, a partir do estabelecimento de alguns processos padronizados. Em conjunto também foi criado o Manual de Marcas do Circuito, que contribuiria para o alinhamento da comunicação interna e externa, bem como das ações de divulgação e marketing.

Ainda com relação à comunicação, o questionário aplicado avaliou qual a opinião dos gestores quanto à comunicação interna do Circuito, considerando os seguintes atores: Estado, ICSM, Espaços e equipes internas, conforme Gráfico 3. Quatro gestores assinalaram que a comunicação precisa melhorar entre o Estado/ ICSM (Núcleo Articulador) e os Espaços, sendo que um desses também sinalizou que a comunicação precisa melhorar dentro dos espaços. E os outros cinco representantes responderam que a comunicação é boa, mas pode melhorar em alguns aspectos.

\section{Gráfico 2 - Avaliação da comunicação interna do Circuito}

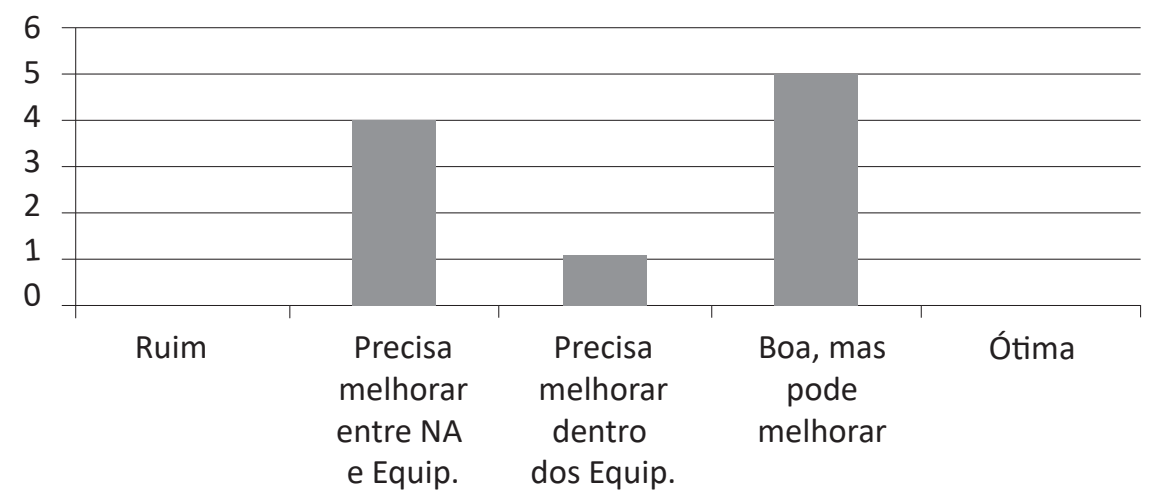

Fonte: elaboração própria

Esses problemas de comunicação entre os espaços foram reafirmados pelo nível de conhecimento que cada um dos gestores tem a respeito dos demais espaços (equipe, estrutura, funcionamento, programação). Apenas um gestor afirmou que possuía alto nível de conhecimento, sendo que dois gestores consideraram ter um conhecimento médio sobre os demais espaços, e os demais afirmaram que o seu nível de conhecimento variava de espaço para espaço. A necessidade da adoção de mais estratégias de comunicação interna foi reforçada, no entanto, quando os gestores foram questionados sobre o nível de conhecimento que acreditavam que 
suas respectivas equipes apresentavam quanto à proposta e estrutura do Circuito. Seis gestores avaliaram que os funcionários de seu espaço apresentavam um conhecimento médio e três gestores avaliaram o nível de conhecimento dos seus funcionários como baixo. Os resultados podem ser vistos, respectivamente, nos Gráficos 4 e 5.

Gráfico 3 - Nível de conhecimento dos gestores sobre os demais equipamentos

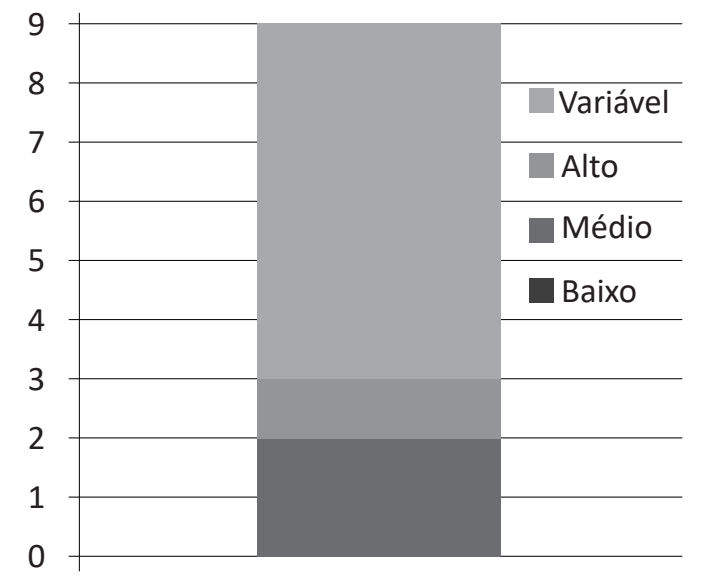

Fonte: elaboração própria

Gráfico 4 - Nível de conhecimento dos funcionários sobre o Circuito, segundo a percepção dos gestores

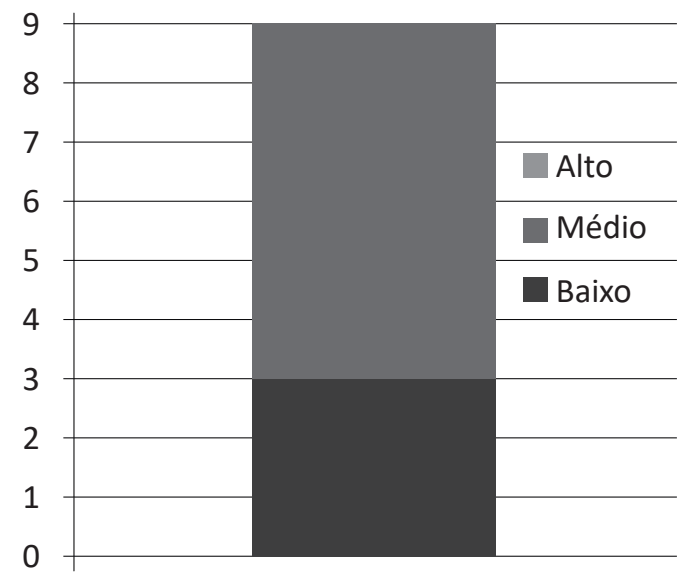

Fonte: elaboração própria

Considerando que a governança em rede pressupõe a interlocução entre diferentes atores, tem-se que o conhecimento mútuo é a base para esse modelo de 
gestão. É precária a articulação em rede entre diferentes atores que não conhecem de maneira adequada todos os atores envolvidos em um projeto. A situação apresentada pelos Gráficos 3 e 4 pode indicar que, mesmo que o Circuito adote estratégias de gestão em rede, essas estão atingindo apenas, e parcialmente, o nível mais estratégico/gerencial do projeto.

Os gestores dos espaços foram ainda questionados com relação à percepção dos fatores que poderiam influenciar negativamente a integração do projeto, prejudicando a perspectiva de Governança em Rede. Os fatores que mais dificultam o fortalecimento da identidade do Circuito e a sua integração destacados pelos gestores foram: a heterogeneidade dos espaços, as diferenças de interesse/ conflitos entre os atores envolvidos e a existência de espaços públicos e privados, conforme pode ser visto no Gráfico 5.

\section{Gráfico 5-Quais fatores mais dificultam a integração do Circuito e o fortalecimento de sua identidade?}

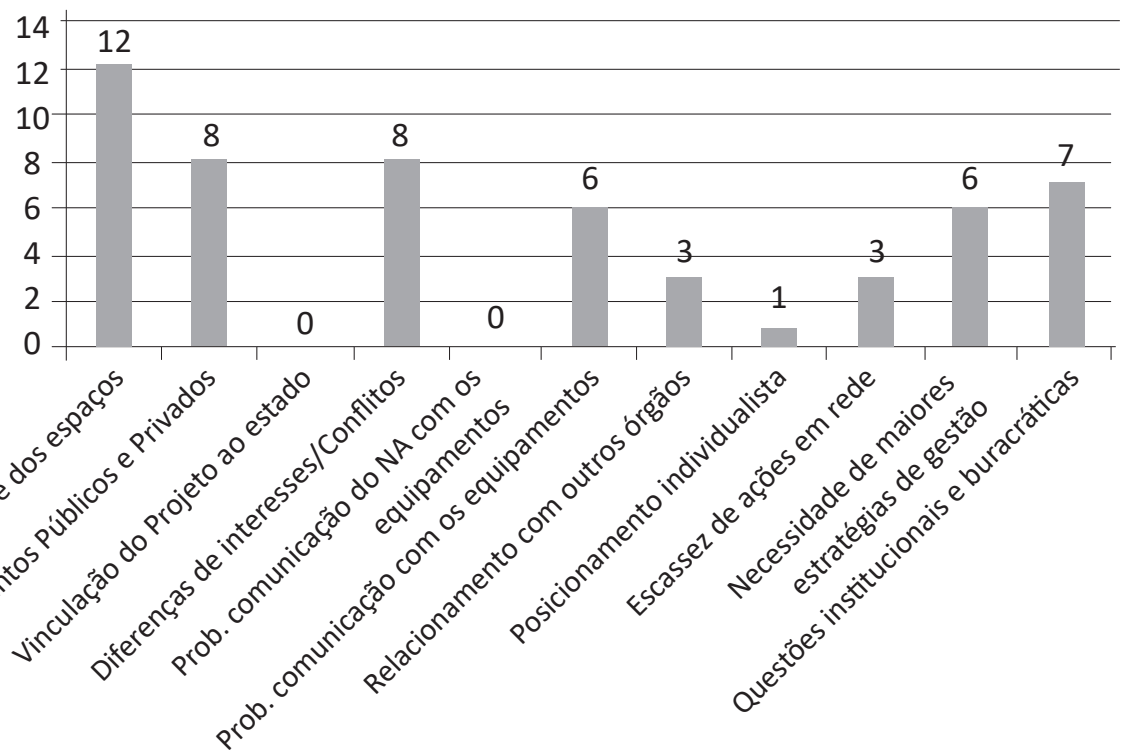

Fonte: elaboração própria

Cabe ressaltar que os três fatores que mais dificultam a integração do Circuito relacionam-se à diversidade, elemento inerente à concepção do Circuito, inclusive pela atuação do setor privado, justificada para atender melhor as diretrizes da governança em rede, ao proporcionar à sociedade, o acesso e a manutenção dos espaços públicos a um custo menor (Plano Geral, 2005; Oliveira, 2008). Essa diversidade justifica a adoção de um modelo de governança do tipo NAO, conforme 
definido por Provan e Kenis (2007), tendo em vista que esse modelo é adequado para os casos em que o nível de confiança e o consenso de metas são moderados e a interpendência das atividades é alta, exigido um alto nível de competência de rede.

Grande diversidade é apresentada no modelo de gestão e financiamento adotado pelo Circuito, esboçado em seu Plano Geral (2005). Nesse Plano, previase já a gestão central do projeto por uma entidade específica, com a atribuição de administrar os serviços e atividades comuns do conjunto, mas se designava que cada equipamento seria administrado por uma entidade gestora própria, estabelecida por convênio e/ou concessão com o Governo de Minas Gerais, ficando responsável pela manutenção e financiamento de seus espaços, cedidos pelo estado.

Essa concepção de financiamento e gestão é essencial para garantir não só os recursos e o dinamismo desejados, mas também a integridade física e simbólica da região, bem como amplas oportunidades de participação, e a necessária pluralidade de visões, de tendências e de preferências no que diz respeito às atividades e às programações desenvolvidas (PLANO GERAL, 2005).

O financiamento e a gestão do Circuito deveriam contemplar e buscar ativamente, em todas as suas etapas, a participação da comunidade, das empresas e dos diversos níveis de governo através do estabelecimento de parcerias dos tipos público-público (com outras esferas do governo), público-privado (com empresas e entidades da sociedade civil) e de cooperação internacional. Os modelos de parceria poderiam variar de acordo com as peculiaridades de cada caso, gerando, assim, já em sua origem, particularidades que dificultariam a posterior gestão em rede do Circuito.

Os documentos firmados com os espaços são, pois, diferentes entre si. Como exemplo, o Memorial Minas Gerais Vale, o Museu das Minas e do Metal, e o Centro Cultural Banco do Brasil (CCBB) funcionam a partir de um termo de convênio, enquanto a Cemig e a UFMG realizam a gestão, respectivamente, do Centro de Arte Popular e do Espaço do Conhecimento, a partir de um Convênio de Cooperação Técnica e Financeira. E até mesmo quando consideramos equipamentos que assinaram o mesmo tipo de instrumento jurídico, não há um padrão único, havendo diferenças entre as cláusulas.

Como resultado dessa diversidade presente no Circuito Liberdade, o Estado de Minas Gerais, por meio da SEC, passou a se encontrar no topo de relações público-privadas complexas cujas dimensões ainda não são claras. Nesse tipo de relação, as conexões são mais flexíveis, sendo a administração pública responsável por um sistema sobre o qual se tem pouco controle real; e quanto mais as redes aumentam, maior é a vulnerabilidade da capacidade de gestão do núcleo central (RHODES, 1996). 
Essa é a situação percebida no Circuito, cujo maior desafio de gestão está relacionado justamente ao alinhamento e à articulação de todos os atores envolvidos, mobilizando-os para manter a unidade proposta pelo projeto (ALVES, 2009). Além disso, como já exposto, a necessidade de estratégias relacionadas a uma governança em rede, que permita uma maior integração dos espaços que compõem o Circuito é, de certa forma, uma demanda recente. A proposta precursora de Francelino Pereira, em 1998, e o Plano Geral do Circuito, em 2005, haviam apenas esboçado diretrizes gerais de gestão do Circuito, estabelecendo a existência de uma entidade coordenadora central e entidades gestoras próprias para cada espaço cultural.

Nesse contexto diversificado, tem-se a importância de aplicação de incentivos e instrumentos que visem à integração das políticas (O'TOOLE, 2010; RADIN, 2010), mas se sabe que nenhum conjunto de normas e incentivos planejado é autoaplicável, necessitando de certo grau de liderança e habilidade do núcleo central, capacidade de identificar alternativas de barganha, e, principalmente, a utilização de estratégias específicas de cooperação (O’TOOLE, 2010).

Talvez a efetiva implementação dessas ações, características da perspectiva de governança em rede, ainda seja prejudicada pelo apego às questões formais e burocráticas. Isso, pois, conforme pode ser visto no Gráfico 5, o quarto fator visto como dificultador para a integração do Circuito refere-se às questões burocráticas e institucionais - típicas de uma estrutura tradicional de administração pública, que impacta na celeridade de contratações, compras, divulgação etc., atividades fundamentais, por exemplo, para uma comunicação e programação cultural dinâmicas, como exigido pela proposta do Circuito Liberdade. Percebe-se, portanto, a coexistência de uma dinâmica de ação governamental que pretende ser avançada, utilizando-se de mecanismos de rede com atores bastante diversificados, com uma administração burocrática, mais formal e engessada. Tal coexistência certamente impacta a eficácia da gestão em rede do Circuito Liberdade.

Ressaltam-se também os desafios relacionados ao envolvimento do Núcleo Articulador e dos gestores dos espaços com outros órgãos e entidades, e com outras esferas da sociedade, que apenas são consideradas em ações isoladas. Quando questionados sobre quais elementos do Circuito gostariam de compreender melhor, seis dos nove gestores afirmaram que gostariam de compreender melhor o relacionamento com outros órgãos/entidades, tais como lepha-MG, Secretaria Municipal Adjunta de Regulação Urbana (SMARU) e PBH, ao passo que um gestor classificou o relacionamento com outros órgãos/entidades como um fator que dificulta a integração do Circuito e o fortalecimento de sua identidade.

Outro ponto a ser destacado é o pouco compartilhamento das metas e produtos com os gestores dos espaços culturais. O fato de apenas dois dos nove gestores 
apontarem que gostariam de compreender melhor as metas, marcos e produtos do Circuito para com o Estado não indica que os demais já o compreendem bem, mas sim, como pode ser percebido pela observação direta, que os gestores, em geral, não têm conhecimento e nem compreendem a dimensão do acordo que o Circuito apresenta para com o Estado.

De todos os indicadores, metas e produtos definidos para o Circuito, apenas os números de visitantes são repassados para os espaços. Apesar de existirem metas mensais e anuais de visitação do Circuito que devem ser informadas ao Estado, não há nenhum compartilhamento de metas com os espaços culturais, que apenas informam os dados coletados, sem nenhum compromisso nesse sentido.

Em contextos de rede, o governo deve desempenhar, na verdade, um papel de facilitador, não procurando atingir diretamente seus próprios objetivos, mas ajudando para que os objetivos comuns da rede sejam alcançados (RHODES, 1996, Provan; KenIS, 2007). O papel de facilitador, no caso do Circuito, pode ser atribuído não apenas ao Governo, mas sim ao Núcleo Articulador como um todo. Essa estrutura, porém, ainda parece um pouco confusa para os gestores dos espaços culturais, uma vez que cinco gestores gostariam de compreender melhor o papel da equipe do Estado. Além disso, um dos gestores informou que deveria deixar cada vez mais clara qual a autonomia dos espaços e qual a relação com o Estado.

Tais defasagens poderiam ser sanadas, por exemplo, por meio das reuniões do Comitê Gestor, organizadas e mediadas pelo Núcleo Articulador. Quando perguntados sobre a importância e utilidade do Comitê Gestor, todos os representantes dos espaços responderam ser muito importante/útil (quatro dos nove respondentes) ou que é fundamental (os outros cinco gestores). Dado que, diferentemente do Planejamento Estratégico (item mais votado), as reuniões do Comitê ocorrem com uma frequência constante (mensal), este pode ser considerado o momento oportuno e um instrumento fundamental para uma gestão em rede efetiva do Circuito. Para tanto, é necessário o estabelecimento adequado de fluxos de informação, prioridades e responsabilidades para o desenvolvimento dos trabalhos.

Contudo, ao avaliar o funcionamento e eficácia das reuniões de Comitê Gestor, as respostas não apresentaram tal positividade. Seis gestores responderam que o Comitê atende bastante ao que se propõe, mas os demais (três) assinalaram que atende razoavelmente ao que se propõe. Esse resultado indica que aperfeiçoamentos precisam ser empregados no funcionamento do Comitê Gestor, principalmente, como pode ser percebido na observação participante, no sentido de uma maior atuação deliberativa dos gestores; as reuniões acabam sendo 
majoritariamente expositivas, nas quais a coordenação geral repassa informações, alinhamentos ou solicitações para os gestores.

No que se refere à relação Estado-sociedade no Circuito Liberdade, foram pensadas, e até mesmo executadas, algumas ações voltadas para outros atores da rede que compõem o Circuito, que vão além dos gestores dos espaços culturais. Pode-se destacar, por exemplo, o Projeto Vizinhança, no qual se buscou uma relação mais estreita com os moradores dos edifícios residenciais do entorno da Praça.

O envolvimento da população em projetos de governança em rede é outro ponto bastante considerado em qualquer referencial teórico sobre a nova abordagem da governança, ao garantir o desenvolvimento da cidadania e participação popular (Rhodes, 1996; Denhardt; Denhardt, 2000; Paula, 2005; Carneiro; Menicucci, 2011). A participação da população no Circuito, porém, se limita a algumas pesquisas de opinião realizadas ao longo dos anos ${ }^{8}$, além da interação entre visitante e acervo ou programação que ocorre em todos os espaços culturais.

Conforme expresso no Planejamento Estratégico do Circuito, deveriam ser considerados como pontos fundamentais: as ações democráticas, a interdisciplinaridade, a participação pública dos cidadãos, fóruns abertos de apresentação e participação dos trabalhos à população, e a participação de entidades da sociedade civil organizada. Mecanismos de participação ativa apenas poderão ser mais bem desenvolvidos na medida em que as demais estratégias de Governança em Rede do Circuito se consolidarem integralmente. Apesar das dificuldades, não se pode desconsiderar o trabalho realizado e o empenho do Núcleo Articulador para a gestão em rede do Circuito. Quatro gestores afirmaram que estão sendo adotados estratégias/ações para melhorar a integração do Circuito. Esse resultado

\footnotetext{
${ }^{8}$ Em 2004, quando o projeto do Circuito ainda estava sendo planejado, a empresa Vox Populi foi contratada pelo Estado para realizar uma pesquisa (quantitativa e qualitativa) de público, com os objetivos de: determinar opiniões, expectativas e sugestões acerca da proposta de transformação da região da Praça da Liberdade em um Complexo Cultural e avaliar o impacto que tal projeto traria sobre a vida cultural e social de Belo Horizonte. Os resultados da pesquisa basearam muitas das ações que foram adotadas para a elaboração e a implantação do Circuito, dando origem inclusive ao Plano Geral de 2005.

Uma nova pesquisa de público da Vox Populi foi contratada em 2012 pelo ICSM com o objetivo principal de avaliar o conhecimento, as percepções e opiniões da população sobre o Circuito, além da importância do projeto para Belo Horizonte, o reconhecimento da marca do Circuito e o que as pessoas esperam de um Circuito Cultural. A pesquisa foi repetida em 2014, antes do ICSM deixar a cogestão, de modo a permitir uma análise da evolução do Circuito nos anos de sua gestão.

A partir de 2016, foi criada a Pesquisa de Público do Circuito Liberdade, elaborada internamente, com o objetivo geral de identificar o perfil do usuário do Circuito Liberdade e a qualidade da infraestrutura e dos serviços prestados pelos espaços, e aplicada anualmente (3a edição realizada em 2018). Essa pesquisa se diferenciou das anteriores por ser feita apenas com os visitantes do Circuito e não com a população de Belo Horizonte de uma forma geral.
} 
é reflexo das reuniões de Comitê Gestor, das ações de comunicação e programação cultural, e de todos os outros instrumentos e estratégias utilizados.

Anteriormente à realização deste trabalho, pensava-se que os gestores dos espaços teriam a dificuldade de entender que fazem parte de um Projeto Estratégico, quais as implicações disso e qual o papel de cada um nesse contexto, apresentando certa resistência diante de intervenções por parte do Governo. No entanto, oito dos nove gestores que responderam ao questionário, afirmaram que compreendem totalmente o que significa fazer parte do Projeto Estratégico Circuito Cultural Praça da Liberdade; apenas um respondeu compreendo razoavelmente / em parte; e em outra pergunta, também apenas um gestor marcou que gostaria de compreender melhor o significado de Projeto Estratégico.

Ao serem questionados acerca de como cada espaço contribui ou poderia contribuir para a integração do Circuito, os gestores responderam: por meio da realização e desenvolvimento de projetos e atividades em conjunto; compartilhando expertises e experiências; participando efetivamente dos Comitês e/ou em outras ações em rede.

A percepção de unidade entre os gestores dos espaços culturais também pode ser percebida em suas respostas com relação aos diversos benefícios, para os seus respectivos espaços, de fazer parte do Circuito, destacando questões como: a interação e o fortalecimento do grupo, a sinergia de ações, e a possibilidade de participação e de parcerias para realização de atividades e ações. A maior visibilidade foi, inclusive, o benefício mais apontado pelos gestores. O compartilhamento / intercâmbio de conhecimentos, experiências e expertises também foi bastante citado sob diversas formas. Ao mesmo tempo, o compartilhamento de conhecimentos e experiências também é apontado por alguns espaços como uma forma de contribuírem para o fortalecimento da identidade do Circuito como um todo.

No espaço disponibilizado no questionário para comentar algo que considerassem relevante para o tema, alguns gestores deixaram contribuições para a análise deste trabalho, conforme pode ser vista na seguinte transcrição:

Acredito muito no projeto, percebo que desde que comecei a participar, o grupo está mais coeso, mas penso que deve ser mais trabalhado a questão: 'Equipe Circuito' (Respondente 3).

Dessa forma, por mais que, segundo a percepção geral dos gestores, o Núcleo Articulador tenha adotado estratégias para a integração do Circuito, ainda seriam necessárias mais estratégias e aperfeiçoamentos no sentido de uma governança em rede, já que ainda predominam ações e iniciativas isoladas. 


\section{Considerações finais}

O Circuito Liberdade foi desenvolvido como um projeto estratégico do Governo de Minas Gerais, cuja estrutura de financiamento e gestão previu o estabelecimento de parcerias entre instituições públicas, privadas e do terceiro setor, seguindo uma tendência de desenvolvimento de uma governança em rede. No entanto, diante da complexidade que caracteriza esse sistema que foi gerado, o maior desafio do Circuito é justamente a gestão dos espaços culturais heterogêneos que o compõem, relacionado ao alinhamento e à articulação de todos os atores envolvidos, mobilizando-os para manter a sua unidade proposta. A consolidação do projeto exige uma atenção especial à sua gestão integrada e à intensificação e continuidade de estratégias de gerenciamento em rede, não desconsiderando as importantes particularidades de cada parceiro.

Cabe destacar que o Circuito é um projeto relativamente novo, e que as preocupações com a sua gestão são ainda mais recentes, tendo como marco o final de 2011, com a realização dos seminários de planejamento estratégico. Desde então, mais ações foram adotadas com vistas à gestão do Circuito como um todo. Desde sua inauguração, a visitação do Circuito cresceu de 463.338 em 2010 para 1.614.250 em 2017 (348,4\% de aumento) ${ }^{9}$, não apenas pela maior divulgação de cada um dos espaços, mas também pela atratividade do projeto como um todo. Por fazerem parte de uma rede, os membros acabam por atrair público não apenas para os seus espaços, mas também para os demais, trazendo benefícios para todos os envolvidos.

À época de realização desta pesquisa, muitos dos instrumentos de governança, aqui denominados governança em rede, por envolverem redes auto-organizadas de atores governamentais e não governamentais em torno de interesses e objetivos comuns, estavam ainda sendo consolidados. Entretanto, no que diz respeito à contribuição deste trabalho para a gestão do Circuito Liberdade, observou-se que os gestores dos espaços culturais reconhecem esses avanços e benefícios de se fazer parte da referida rede, mas que ainda seriam necessárias novas estratégias de integração.

Nesse contexto, tem-se que as principais estratégias no âmbito da governança em rede identificadas no Circuito foram: Planejamento Estratégico, Comitê Gestor, Regimento Interno, Política de Ocupação Cultural e Educativa do Circuito, e Ações de Comunicação e Marketing.

\footnotetext{
${ }_{9}^{9}$ Seguem dados gerais anuais de visitação do Circuito Liberdade: 2010 - 463.338; 2011 - 545.640; 2012 - 720.994; 2013 - 800.367; 2014 - 1.464.626; 2015 - 1.371.946; 2016 - 1.539.492; 2017 - 1.614.250.
} 
Sob uma nova gestão em 2015, algumas estratégias foram mantidas, como o Comitê Gestor, os Comitês específicos, a sinalização externa e o Centro de Informação ao Visitante, enquanto outras foram interrompidas, como o Regimento Interno, o Manual de padronização de marca e a Política de Ocupação Cultural, bem como algumas ações de comunicação e marketing (aplicativo para smartphones, toten informativo etc).

O Planejamento Estratégico, considerado principal ação de governança pelos gestores do Circuito, não foi revisto ou substituído, estando teoricamente ainda vigente, mas, na prática, não chegou a ser utilizado na nova gestão. Novas ações de integração foram realizadas, especialmente eventos em conjunto, nos quais os espaços oferecem salas, programação ou pessoal para participação em eventos definidos pela gestão central, mas sem grandes deliberações.

Posteriormente à observação participante via estágio por um dos autores, este foi efetivado no Circuito, estando presente até o momento (1ㅇsemestre de 2018). A experiência de mais de 4 anos na organização permitiu mudanças na percepção em relação ao projeto do Circuito, à sua gestão e aos resultados da referida pesquisa. Percebe-se que com a saída de um dos atores (ICSM), a rede se tornou menos complexa, mas se acentuaram as características tradicionais de gestão pública de centralização e verticalização de ações e decisões, mudando a configuração da integração. Se antes havia mais um ator, que de certa forma fazia uma mediação entre os interesses do Estado e uma maior compreensão dos interesses dos parceiros privados, na nova gestão os interesses públicos e privados convivem de forma mais direta, acirrando-se com uma maior necessidade de controle e proteção dos mesmos. Caberia aqui, pois, novas pesquisas e analises para a gestão do Circuito desde então, para analisar a qualidade da governança em rede.

De todo modo, um desafio que se mantém desde a época da pesquisa realizada se refere a disseminar para além do nível estratégico do Circuito, a perspectiva de unidade e integralidade do Projeto. Apenas os gestores dos espaços culturais conseguem perceber essa dimensão, enquanto entre os demais funcionários de suas equipes ainda prevalece a desinformação sobre o Circuito como um todo e não há uma sensação de pertencimento. Como pode ser observado pela participação em reuniões dos Comitês específicos, o Circuito não é visto como um projeto conjunto, mas como um ente à parte (no caso, a equipe do lepha-MG, que realiza a gestão geral), que realiza demandas para além das tarefas diárias de cada espaço individualmente.

Sendo assim, quando se fala de governança em rede é preciso avançar para além da implementação de ações formais de integração, sendo necessário criar de fato um maior nível de confiança e de consenso de metas, principalmente, no caso do Circuito em que há grande diversidade entre os membros. 
Adicionalmente, observam-se ainda poucas ações e estratégias na direção de uma maior integração com os demais atores envolvidos, mesmo que indiretamente, como por exemplo, a própria sociedade civil. Um elemento bastante considerado na nova abordagem da governança em rede é justamente o desenvolvimento da participação popular, do controle social e da cidadania, aspectos ainda pouco explorados no Circuito.

Desde 2015, na nova gestão, foi criado um evento chamado Observatório do Circuito Liberdade com o objetivo de estimular a participação do público, no qual são convidados palestrantes para tratar de algum tema e, ao final, é aberto um espaço para questionamentos e dúvidas dos presentes. Tal ação, que ocorre por volta de 3 (três) vezes ao ano, acaba não alcançando o que se propõe, pela limitação do público que se apresenta (entre 15 a 30 pessoas) e pela baixa flexibilidade de fato para o público contribuir para a gestão governamental. Trata-se, mais uma vez, de uma ação formalmente instituída, mas que possui resistências à efetiva busca de participação.

Percebe-se, portanto, que um dos grandes desafios para a operacionalização de uma perspectiva de governança em rede consiste na coexistência de mecanismos de uma velha administração com uma nova administração. A realização efetiva de uma gestão em rede no setor público exige que o Estado abra mão de seu poder hierárquico e centralizador na formulação e implementação de políticas públicas, que na prática encontra resistências.

Diante do exposto e retomando o objetivo desta pesquisa, conclui-se que o Circuito Liberdade se trata de um projeto ousado que prevê uma complexa rede de atores governamentais e não-governamentais, seguindo as expectativas de uma Governança em Rede, que pode ser utilizado como exemplo para outras experiências pelas estratégias de integração já empregadas e pelos benefícios de rede já alcançados e confirmados em pesquisa realizada com os gestores dos espaços culturais.

É possível aprender também com os desafios aqui analisados e que persistem na experiência do Circuito. A reflexão sobre tais desafios constitui ainda a possibilidade de aprendizado para o próprio Circuito Liberdade, no sentido de implementar estratégias que efetivamente garantam uma gestão mais democrática e participativa do projeto.

Reafirma-se ainda a necessidade de novas pesquisas e análises atualizadas sobre a governança em rede do Circuito Liberdade para além do presente artigo. 


\section{Referências bibliográficas}

ALVES, Laís Fonseca. Estruturas organizacionais inovadoras na gestão pública: o caso do Projeto Estruturador Centro da Juventude de Minas Gerais - Plug Minas. 94f. Monografia (Curso de Graduação em Administração Pública) - Fundação João Pinheiro, Escola de Governo Professor Paulo Neves de Carvalho, Belo Horizonte, 2009.

BINGHAM, Lisa Blomgren; NABATCHI, Tina; O'LEARY, Rosemary. The New Governance: practises and processes for Ssakeholder and citizen participation in the work of government. In: Public Administration Review. Set/Out 2005, v. 65, n. 5, p. 547-558, 2005.

BRUGUÉ, Q. Modernizar la administración desde la izquierda: burocracia, nueva gestión pública y administración deliberativa. Revista del Clad Reforma y Democracia. Caracas. n. 29, 2004.

Carneiro, R.; Menicuccl, T. M. G. Gestão pública no século XXI: as reformas pendentes. Texto para discussão 1686. Brasília: Ipea, 2011.

DenhardT, Robert B.; DenhardT, Janet Vinzant. The New Public Service: Serving Rather than Steering. In: Public Administration Review. Arizona State University, v. 60, n. 6.p.549-559, 2000.

FonseCA, Mireille Cássia. Da Praça do Poder à Praça da Cultura: um Estudo sobre o Circuito Cultural Praça da Liberdade. 118f. Monografia (Conclusão do Curso de Turismo) - Universidade Federal de Minas Gerais - UFMG, Belo Horizonte. 2009.

KLIJN, Erik-Hans; SKELCHER, Chris. Democracy and Governance Networks: Compatible or not? In: Public Administration, v. 85, n. 3, p. 587-608, 2007.

Minas GeraIS. Decreto no 43.263, de 11 de abril de 2003. Institui Comissão Especial de Estudos do Centro Cultural da Praça da Liberdade e dá outras providências. Disponível em: <http:||www.almg.gov.br>. Acesso em: 06 Nov. 2014.

Minas Gerais. Plano Geral do Circuito Cultural Praça da Liberdade. Belo Horizonte, 2005.

Minas Gerais. Secretaria de Estado da Cultura. Termo de Parceria no 032/2012. Belo Horizonte, 2012.

Minas GeraIS. Secretaria de Estado de Planejamento e Gestão (coord.). Plano Mineiro de Desenvolvimento Integrado (PMDI) 2003-2020. Belo Horizonte, 2003.

Oliveira, Isa Maria Marques de Oliveira. Política de proteção do patrimônio cultural: Aanálise da concepção e posicionamento dos principais atores envolvidos na implementação do Projeto Estruturador Circuito Cultural da Praça da Liberdade. 106f. Monografia (Curso de Graduação em Administração Pública) - Fundação João Pinheiro, Escola de Governo Professor Paulo Neves de Carvalho, Belo Horizonte. 2008.

O'TOOLE, Laurence J. Relações Interorganizacionais no Processo de Implementação. In: Peters, B. Guy; Pierre, Jon. (Org.). Administração Pública Coletânea. São Paulo: Editora Unesp; Brasília, DF: Enap. Cap. 10, p. 229-248, 2010. 
PAULA, A.P.P. Por uma nova gestão pública: limites e potencialidades da experiência contemporânea. Rio de Janeiro: EdFGV. 2005.

PereIRA. Francelino. Espaço Cultural da Liberdade: Praça da Liberdade - Belo Horizonte: capital do século: 12/12/1897-12/121997. Brasília: Senado Federal, Gabinete do Senador Francelino Pereira, 1998.

Planejamento Estratégico. Belo Horizonte: Circuito Cultural Praça da Liberdade, 2011-2012.

Política Cultural e Educativa do Circuito. Belo Horizonte: ICSM, 2013.

Provan, K. G.; FISH, A.; SYDOW, J. (2007). Interorganizational networks at the network level: a review of the empirical literature on whole networks. Journal of Management, v. 33, n. 3, p. 479-516.

Provan, K.G.; KenIS, P. (2007). Modes of network governance: structure, management and effectiveness. Journal of Public Administration Research \& Theory, v.18, n. 2, p.229-252.

RADIN, Beryl A. Os Instrumentos da Gestão Intergovernamental. In: PETERS, B. Guy; PIERRE, Jon. (Org.). Administração Pública Coletânea. São Paulo: Editora Unesp; Brasília, DF: Enap, Cap. 27, p. 597-618, 2010.

RHODES, R. A. W. The new governance: governing without government in political studies. University of Newcastle-upon-Tyne, XLIV. p. 652-667, 1996.

SLOMSKI, Valmor; Mello, Gilmar Ribeiro de; FILHO, Francisco Tavares; MACÊDo, Fabrício de Queiroz. Governança corporativa e governança na gestão pública. São Paulo: Atlas, 2008.

SMITH, Andy. Governança de Múltiplos Níveis: O que é e como pode ser estudada. In: Peters, B. Guy; PIerre, Jon. (Org.). Administração Pública Coletânea. São Paulo: Editora Unesp; Brasília, DF: Enap, Cap. 28, p. 619-635, 2010.

STOKER, Gerry. Governance as theory: five propositions. Oxford: Blackwell Publishers. Unesco, p. 17-28, 1998.

VIGODA, Eran. From Responsiveness to collaboration: governance, citizens and the next generation of public administration. Public Administration Review, Set-Out 2002, v. 62, n. 5. p. 527-540, 2002. 